\title{
Potential roles of stem cell marker genes in axon regeneration
}

\author{
Jinyoung Lee ${ }^{1}$ and Yongcheol Cho $\mathbb{B}^{1}$
}

\begin{abstract}
Axon regeneration is orchestrated by many genes that are differentially expressed in response to injury. Through a comparative analysis of gene expression profiling, injury-responsive genes that are potential targets for understanding the mechanisms underlying regeneration have been revealed. As the efficiency of axon regeneration in both the peripheral and central nervous systems can be manipulated, we suggest that identifying regeneration-associated genes is a promising approach for developing therapeutic applications in vivo. Here, we review the possible roles of stem cell marker- or stemness-related genes in axon regeneration to gain a better understanding of the regeneration mechanism and to identify targets that can enhance regenerative capacity.
\end{abstract}

\section{Introduction}

Neuronal competence of axonal growth is regulated by transcriptional changes in response to injury ${ }^{1}$, and multiple genes responsible for axon regeneration have been identified by comparative gene expression profiling ${ }^{2}$. As the regenerative potential of injured neurons is distinctively regulated by both intrinsic and extrinsic factors $^{3-7}$, differentially expressed genes under regenerative or nonregenerative conditions are considered potential targets for understanding the mechanism of axon regeneration that is orchestrated by injury-responsive genes ${ }^{8-10}$. Therefore, manipulating regeneration-associated genes (RAGs) is a potential method for developing approaches that promote regeneration. Diverse experimental designs have been utilized for comparative investigations of differential gene expression, revealing core genes that regulate regenerative capacity.

Tedeschi et al. reported three paradigms that produce the conditions for differential axonal outgrowth at different embryonic development stages, different regenerative stages of adult DRG neurons, and preconditioned adult DRG neurons ${ }^{11}$. They made a comprehensive list of

Correspondence: Yongcheol Cho (ycho77@korea.ac.kr)

'Laboratory of Axon Regeneration \& Degeneration, Department of Life Sciences, Korea University, Anam-ro 145, Seongbuk-gu, Seoul 02841,

Republic of Korea genes that are differentially regulated based on the environmental conditions and are potential targets for manipulation that promotes axon regeneration. They identified Cacna $2 d 2$ as a negative regulator of regeneration and presented a new method for promoting axon regeneration in vivo, as the pharmacological inhibition of Cacna $2 d 2$ resulted in significantly improved regeneration in vivo; this work suggests that manipulating the expression of identified genes is a suitable strategy for promoting axon regeneration.

Stemness refers to the ability of a cell to perpetuate its lineage, produce differentiated daughter cells, and selfregulate its proliferation or regeneration ${ }^{12}$. Stemness is a manipulatable physiological characteristic, and the use of engineered pluripotent stem cells has ushered in a new era of regenerative medicine ${ }^{13,14}$. In addition, direct reprogramming technologies are emerging as novel approaches for treating neurological disorders and neural injury ${ }^{15-17}$. The elucidation of cellular stemness has resulted in the identification of genes that are specifically expressed in diverse types of stem cells. However, understanding how these genes regulate cellular stemness remains unclear. In addition, it remains unknown whether manipulating stem cell marker genes in nonstem cells might potentiate particular biological functions, such as regeneration and how they might be used to understand 
the mechanism by which stem cell marker genes mediate their effects.

In relation to the potential function of stem cell marker genes and axon regeneration, research has recently shown that Prom1, a marker of stem cells, is expressed by dorsal root ganglion (DRG) neurons and is downregulated when neurons mature in adult mice ${ }^{18}$. Prom 1 overexpression in the DRG of adult mice in vivo resulted in the promotion of axon regeneration after sciatic nerve injury, implying that stem cell marker genes are potential candidates for developing new methods that enhance neuronal regenerative capacity. Here, we review neuronally expressed stem cell marker genes and their roles in axon regeneration and propose a new idea for establishing neuroregenerative applications related to cellular stemness (Fig. 1).

\section{SRY-box transcription factor 9 (Sox9)}

Sox9 encodes a transcription factor that is expressed in pluripotent, fetal, and adult stem and progenitor cells. Sox 9 expression is regulated by signal transduction pathways, such as the Sonic hedgehog pathway, Notch signaling, TGF- $\beta$ pathway, and Fgf9-mediated signaling ${ }^{19}$. Sox9 is downregulated in embryonic DRG tissues ${ }^{11}$. Sox 9 is expressed in astrocytes and ependymal cells in the neurogenic regions of adult human and mouse brains ${ }^{20}$. The expression of Sox 9 has been reported to be sustained across the Schwann cell lineage from E9 to E18.5 and at postnatal P7 and P65 in the mouse sciatic nerve ${ }^{21}$. In addition, non-myelinating Schwann cells also express Sox 9 after sciatic nerve injury. The expression of Sox 9 with characteristics of neural stem cells in the adult mouse brain was initially identified in the Bergmann glia population $^{22}$. In embryonic DRG neurons, developmental downregulation was reported from E12 to E17 via RNASeq analysis ${ }^{11}$. Sox 9 is critical for the injury-responsive upregulation of genes associated with glial scar formation, which is a major barrier to axon regeneration in the $\mathrm{CNS}^{23}$; the genes associated with glial scar formation include those that encode chondroitin sulfate proteoglycans (CSPG). Tamoxifen-inducible Sox 9 deletion in adult mice has been reported to result in reduced CSPG production and small scar sizes in the spinal cord after injury, subsequently resulting in improved motor function recovery $^{23}$ (Fig. 1d). These results indicate that inhibiting Sox9 expression in glial cells is a potential approach for promoting functional recovery. Moreover, Sox 9 is upregulated in both DRG and sciatic nerves after axotomy ${ }^{24,25}$. Therefore, the roles of injury-upregulated Sox 9 expression must be investigated in PNS regeneration models.

\section{Musashi RNA-binding protein (Msi1)}

Msi1 is an RNA-binding protein (RBP) that regulates the translation of target mRNA and is known to be enriched in the $\mathrm{CNS}^{26-28}$. Musashi1 is required for the proliferation of neural progenitor cells, including CNS stem cells ${ }^{29}$; it binds to Robo3 to regulate posttranscription, a phenomenon that is essential for the midline crossing of pre-cerebellar neurons ${ }^{30}$ (Fig. 1e). In an investigation on Msi1 in the ependymal cells of amphibian models wherein the levels of Msi1 in the regeneration competent and noncompetent stages of Xenopus decreased, Msi1 was found to be a robust marker of regeneration ${ }^{31}$. In addition, regeneration competent amphibians such as Axolotl and Xenopus exhibit different states of spinal cord ependymal cells. Axolotl express Msi1 in embryonic and juvenile stages and not in adult stages; however, Msi1 is upregulated after injury ${ }^{31}$. Moreover, in a functional screening, C. elegans msi- 1 was identified as critical for axon regrowth ${ }^{32}$. These reports indicate that Msi1-dependent cellular stemness may be a potential target for manipulation to promote axon regeneration. As RBPs participate in the posttranscriptional regulation of diverse mRNA stability, translational control, and localization ${ }^{33}$, Musashi-binding mRNAs that are associated with axon regeneration need to be identified for the elucidation of molecular mechanisms.

\section{Prominin1 (Prom1)}

Prom1, a pentaspan membrane glycoprotein known to bind cholesterol, is used as a normal or cancer stem cell marker ${ }^{34-36}$ and is required for the formation of membrane protruding structures, such as tunneling nanotubes $^{37}$. As genetic deletion of Prom1 causes significant neural defects, such as retinal degeneration, a reduction in the number of neurons in the brain, and walking problems $^{38-41}$, Prom 1 might have specific roles in neuronal tissues. In addition, transplanting prominin1-positive cells obtained from peripheral blood into an injured spinal cord enhanced angiogenesis, astrogliosis, and axon growth in damaged tissue, which led to the functional recovery of mice ${ }^{42}$. These results indicate that prominin1regulated cellular physiology may be related to neural integrity and regeneration ${ }^{43-45}$. Comparative RNA-Seq analysis revealed that Prom1 expression is developmentally downregulated in DRG neurons ${ }^{11}$, although it remains expressed in adult stages ${ }^{18}$. Furthermore, it was found that Prom1 is critical for the differential regulation of a set of genes associated with cholesterol metabolism. Prom1 overexpression promotes axon regeneration in vitro and in vivo and is mediated by the Smad pathway via the downregulation of cholesterol metabolism-related gene expression ${ }^{18}$. In addition, a reduction in cholesterol in DRG neurons significantly enhances axonal regeneration in vitro, suggesting that neuronal cholesterol level may be a potential target to manipulate the competence of axonal growth ${ }^{18}$. Although Jinyoung et al. showed that prominin1 interacts with ALK4, a receptor tyrosine kinase 


\begin{tabular}{|c|c|c|c|c|c|}
\hline Transmembrane & Type & $\begin{array}{l}\text { Stem cell-related } \\
\text { expression }\end{array}$ & Model & $\begin{array}{l}\text { Embryonic } \\
\text { stage }\end{array}$ & Adult stage \\
\hline a. Prominin1(Prom1) & Glycoprotein & $\begin{array}{l}\text { Normal / cancer } \\
\text { stem cells }\end{array}$ & DRG in mouse & & \\
\hline Pathway & \multicolumn{3}{|c|}{ 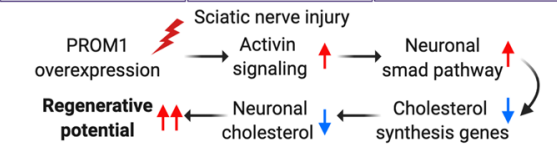 } & & \\
\hline b. Notch Receptor 1 & Receptor & $\begin{array}{l}\text { Cancer stem cell } \\
\text { marker }\end{array}$ & C. elegans & & \\
\hline Pathway & \multicolumn{3}{|c|}{ Notch signaling $\downarrow \longrightarrow \underset{\text { regeneration }}{\text { Axon }} \uparrow \uparrow$} & & \\
\hline Axotomy & \multicolumn{3}{|c|}{$\begin{array}{c}\text { Notch1 mRNA } \\
\text { and protein }\end{array} \uparrow \uparrow \longrightarrow \begin{array}{c}\text { In a mouse Spinal cord } \\
\text { injury model }\end{array}$} & & \\
\hline c. CD44 Molecule & Glycoprotein & $\begin{array}{l}\text { Cancer stem cell } \\
\text { marker }\end{array}$ & $\begin{array}{l}\text { Embryo/Sciatic } \\
\text { nerve in mouse }\end{array}$ & & \\
\hline Pathway & \multicolumn{3}{|c|}{$\begin{array}{l}\text { embryonic retinal explant model } \\
\text { CD44 } \longrightarrow \text { Retinal axon growth } \downarrow\end{array}$} & & \\
\hline Axotomy & \multicolumn{3}{|c|}{$\begin{array}{c}\text { Sciatic nerve } \\
2 \mathrm{hr} \sim 72 \mathrm{hr}\end{array} \longrightarrow \mathrm{CD} 44 \uparrow \uparrow \begin{array}{c}\text { In both proximal and distal } \\
\text { part of transected nerves }\end{array}$} & & \\
\hline I\& $\begin{array}{c}\text { Non-transmembrane } \\
\text { protein }\end{array}$ & Type & $\begin{array}{l}\text { Stem cell-related } \\
\text { expression }\end{array}$ & Model & $\begin{array}{l}\text { Embryonic } \\
\text { stage }\end{array}$ & Adult stage \\
\hline $\begin{array}{c}\text { d. SRY-Box Transcription } \\
\text { factor } 9\end{array}$ & $\begin{array}{l}\text { Transcription } \\
\text { factor }\end{array}$ & $\begin{array}{l}\text { adult stem cells, } \\
\text { progenitor cells }\end{array}$ & $\begin{array}{l}\text { Embryonic DRG in } \\
\text { mouse }\end{array}$ & & \\
\hline Pathway & \multicolumn{3}{|c|}{$\begin{array}{l}\text { Sox9 deletion } \\
\text { in adult mouse }\end{array} \longrightarrow$ CSPG $\downarrow \longrightarrow \begin{array}{c}\text { Reduced scar } \\
\text { formation }\end{array}$} & & \\
\hline Axotomy & \multicolumn{3}{|c|}{$\begin{array}{c}\text { Sox9 } \\
\text { upregulated }\end{array} \uparrow \uparrow \longrightarrow$ DRG and SN } & & \\
\hline $\begin{array}{l}\text { e. Musashi RNA Binding } \\
\text { Protein }\end{array}$ & $\begin{array}{l}\text { RNA binding } \\
\text { protein }\end{array}$ & $\begin{array}{l}\text { Central nervous } \\
\text { system }\end{array}$ & Amphibian & & \\
\hline Pathway & \multirow{2}{*}{\multicolumn{3}{|c|}{$\begin{array}{c}\text { Msi1 binds to Robo3 mRNA } \\
\begin{array}{c}\text { Robo3-deficient mice } \longrightarrow \text { Robo3 expression } \downarrow \\
\text { Midline crossing/ Neuronal migration } \\
\text { of precerebellar neurons }\end{array} \downarrow \\
\begin{array}{c}\text { Msi-1 } \uparrow \uparrow \\
\text { expression/upregulation }\end{array} \\
\longrightarrow \begin{array}{c}\text { Ependymal outgrowth and } \\
\text { stump-region ependymal cells }\end{array}\end{array}$}} & & \\
\hline Axotomy & & & & & \\
\hline Nestin & $\begin{array}{l}\mathrm{VI} \text { intermediate } \\
\text { filament protein }\end{array}$ & $\begin{array}{l}\text { Dividing cells in the } \\
\text { nervous system }\end{array}$ & $\begin{array}{l}\text { Many types of } \\
\text { cells }\end{array}$ & & \\
\hline Pathway & \multicolumn{3}{|c|}{$\begin{array}{c}\text { Nestin depeletion } \\
\text { from cultured neurons }\end{array} \longrightarrow$ Sema4a $\downarrow \longrightarrow \begin{array}{c}\text { Axonal growth cone } \\
\text { collapse } \text { in vitro }\end{array}$} & & \\
\hline Axotomy & \multicolumn{3}{|c|}{ 24-48hr after Spinal cord injury $\longrightarrow \begin{array}{c}\text { Nestin expression } \\
\text { in the central canal }\end{array}$} & & \\
\hline $\begin{array}{l}\text { g. Minichromosome } \\
\text { maintenance complex } \\
\text { component2 }\end{array}$ & $\begin{array}{l}\text { DNA replication } \\
\text { licensing factor }\end{array}$ & $\begin{array}{l}\text { Normal / cancer } \\
\text { stem cells }\end{array}$ & Zebrafish & & \\
\hline Pathway & \multicolumn{3}{|c|}{$?$} & & \\
\hline Axotomy & $\begin{array}{l}1,3 \text { days after Spir } \\
7 \text { days after Spin }\end{array}$ & $\begin{array}{l}\text { ord injury } \longrightarrow \mathrm{Mcm} \\
\mathrm{rd} \text { injury } \longrightarrow \mathrm{Mcm}\end{array}$ & $\begin{array}{l}\text { expression } \downarrow \\
\text { expression restored }\end{array}$ & & \\
\hline
\end{tabular}

Fig. 1 Illustration of stem cell marker genes that have potential roles in regulating axon regeneration. The schematic presentation describes the relative expression levels by developmental stage. All the references are included in the main text.

regulating Smad-TGF- $\beta$ signaling ${ }^{18}$, the direct role of prominin1 in regulating the expression of a specific set of genes in DRG neurons is still unknown (Fig. 1a). The detailed mechanisms need to be further investigated to understand the functions of Prom1 in neurons and nonneuronal cells, such as cancer stem cells.

\section{Nestin (Nes)}

Nestin is encoded by Nes and is a type VI intermediate filament protein ${ }^{46,47}$. Owing to its high abundance in dividing cells in the nervous system, nestin is extensively used for identifying undifferentiated neuronal cells, although it is transiently expressed by many types of cells 
during developmental stages but is mostly absent as adulthood is approached. Nes is an effective marker of neural stem cells and progenitors, and nestin-positive cells engineered for therapeutic applications have been tested $^{48-51}$. Interestingly, a subpopulation of embryonic cortical neurons has been found to transiently express nestin in its axons ${ }^{50}$. Moreover, nestin expression at the axonal ends of motile structures such as growth cones has been visualized. This observation indicates that nestin expression is not restricted to neuronal progenitor cells but is transiently regulated in neurons at specific developmental stages. In addition, as genetic alterations in neurofilament genes, including $N E F L^{52,53}, N E F 3^{52,53}$, $N E F H^{54}, D M N^{55,56}, V I M^{57}$, and $P R P H^{58}$, have been reported in neurodegenerative diseases such as amyotrophic lateral sclerosis, Charcot-Marie-Tooth 2 and giant axonal neuropathy ${ }^{59-61}$, unidentified roles of Nestin in regeneration must be investigated (Fig. 1f).

\section{Minichromosome maintenance complex component 2 ( $\mathrm{Mcm}$ )}

$\mathrm{Mcm} 2$ is a protein required for genome replication and a key component of the prereplication complex ${ }^{62}$. Mcm2 is involved in the regulation of cell cycle progression in stem cells ${ }^{63-65}$ and is a marker of neuronal stem cells ${ }^{66}$. In gene expression profiling studies, $\mathrm{Mcm} 2$ was found to dynamically respond to injury after introducing spinal cord injury in zebrafish, as its expression was markedly reduced from 1 to 3 days after injury. However, the levels of $\mathrm{Mcm} 2$ returned to basal levels after 7 days and then significantly decreased ${ }^{67}$ (Fig. 1g). These findings suggested that critical factors regulating cell cycle progression, including $\mathrm{Mcm} 2$, are upregulated in response to spinal cord injury within a specific limited time window for regeneration. Interestingly, $\mathrm{Mcm} 2 \mathrm{mRNA}$ and $\mathrm{Mcm} 7$ protein, a member of the Mcm family located at the growth cone, were detected in mice ${ }^{68}$. These findings suggest that $\mathrm{Mcm} 2$ in regenerating axons may have specific functions that are not related to cell cycle progression.

\section{Notch receptor 1 (Notch1)}

Notch1 is required for the self-renewal of hematopoietic stem cells and inhibits differentiation ${ }^{69,70}$. Moreover, Notch 1 is a marker used to distinguish between normal and cancer stem cells ${ }^{71,72}$. In the nervous system, Notch1 is required for neuronal and glial differentiation and activity-induced synaptic plasticity ${ }^{73-75}$. Singleneuron analysis of the regeneration of C. elegans indicated that Notch signaling negatively regulates axon regeneration and that inhibiting Notch signaling improves axon regeneration ${ }^{76}$. Notch acts as an intrinsic neuronal inhibitor of regeneration via canonical activation mechanisms regulated by ADAM metalloprotease.
However, Notch-mediated inhibition has been reported to have a $D S L$-independent function, as DSL/lag-2 did not inhibit but it promoted regeneration. In addition, the mechanism of injury-induced Notch activation is unclear owing to the lack of biochemical evidence describing Notch intracellular domain (NICD) levels upregulation after injury. However, overexpressing NICD inhibits regeneration via transcriptional functions. These results indicate that the target genes regulated by NICD, as well as the molecular mechanism activating Notch in response to injury, must be identified. Moreover, because the Notch pathway is regulated by multiple ligands ${ }^{77}$, injurydependent Notch ligands must also be identified. Importantly, Notch1 mRNA and protein were upregulated in an injury-responsive manner exclusively within neurons in a mouse spinal cord injury model ${ }^{78-80}$, suggesting that the role of injury-responsive Notch1 upregulation needs to be investigated (Fig. 1b).

Direct evidence of NICD-mediated regulation of axon regeneration was reported by a study using a spinal cord injury model of sea lamprey ${ }^{81}$. Romaus-Sanjurjo et al. showed that $G A B O B$ a gamma-aminobutyric acid (GABA) analog and baclofen (a GABA receptor agonist) treatments promoted axon regeneration after spinal cord injury $(\mathrm{SCI})^{82}$. Differential gene expression analysis was utilized to understand the molecular mechanism, and the results showed that $H E S B$ expression in the brainstem was significantly reduced by GABA or baclofen treatment 29 days after $\mathrm{SCI}^{82}$. HESB is one of the primary target genes of the Notch signaling pathway and functions as an effector of NICD ${ }^{83}$, implying that NICD negatively regulates axon regeneration after spinal cord injury via its downstream targets, including HES genes. This research group also showed that gamma-secretase inhibitor PF3804014 treatment reduced the expression of HESB in the brainstem and enhanced axon regeneration ${ }^{83}$. This recent result shows that $H E S B$ is a potential downstream effector of Notch pathway-mediated axon regeneration. In addition, the target genes regulated by HES in response to injury need to be identified to understand the molecular mechanisms of NICD-regulated axon regeneration. In addition, the proteins interacting with NICD need to be investigated in axon injury models to identify their unidentified roles in regulating axon regeneration.

\section{CD44 molecule (CD44)}

CD44 is a transmembrane glycoprotein regulating cellcell interactions. CD44 is a stem cell marker of many types of cancer, such as bladder, breast, colorectal, gastric, head and neck, liver, lung, ovarian, pancreatic, and prostate cancers ${ }^{84}$. CD44 participates in diverse cellular processes, such as cell adhesion and cell migration, by interacting with the extracellular matrix. CD44 mRNA and protein were detected in the adult rat brain, and they 
colocalize with neuronal markers and astrocytes and regulate the structures and functions of dendritic spines ${ }^{85}$. CD44 is involved in the regulation of cytoskeletal reorganization in the nervous system via small GTPases ${ }^{86}$. $C D 44$ inhibits retinal axon growth in vitro in an embryonic retinal explant model ${ }^{87}$. The role of $C D 44$ in axonal regeneration is not yet understood, although CD44 expression is upregulated by axonal injury in a cjun-dependent manner ${ }^{88}$. Recent transcriptome data indicate that $C D 44$ is a DLK-dependent injury-responsive gene, as indicated by the genetic deletion of DLK in sensory neurons in mouse DRG impairing the upregulation of CD44 $\mathrm{mRNA}^{24}$. Notably, CD44 is highly upregulated in the sciatic nerve quickly, within $2 \mathrm{~h}$ of injury, and its levels are sustained for as many as $72 \mathrm{~h}^{25}$. Furthermore, identical marked injury-responsive upregulation of CD44 in both the proximal and distal parts of severed mouse sciatic nerves has been observed, suggesting that the role of $C D 44$ in regenerating and degenerating nerves must be considered $^{25}$ (Fig. 1c). Because CD44 undergoes alternative splicing, which produces multiple isoforms that have different biological functions, the injury-specific upregulated isoforms must be determined to understand the biological functions of $C D 44$ in axon regeneration.

\section{Conclusion}

The elucidation of the mechanism underlying axon regeneration has been accelerated by gene expression profiling. Different biological conditions result in differential efficiency of axon regeneration, which is dependent on both neuronal extrinsic and intrinsic factors ${ }^{5,7,89-91}$. To understand the molecular mechanism of axon regeneration and identify methods for application, injuryassociated gene expression has been utilized. By identifying injury-responsive genes via comparative analysis, the identification of new regulators of axon regeneration has become more feasible. However, recognizing only injuryregulated genes is not enough to define potential candidate genes or pathways for promoting axon regeneration because the differential expression of particular genes from injured neurons in experimental models is not always associated with neuronal regenerative capacity. Rather, a large number of DEGs identified through comparative analysis may simply display the transcriptomic landscape of injured neurons, which implies that additional ideas need to be considered for finding the targets for manipulation. Moreover, because it is still unclear which biological properties need to be augmented to enhance regeneration, the specific cellular function to be manipulated needs to be determined when we utilize target genes identified via DEG analysis.

Here, we review a group of genes involved in cellular stemness as target genes for studying axon regeneration.
A set of genes that are significantly upregulated in stem cells have been identified and categorized as stem cell markers. However, the molecular functions of the individual genes in this set are still under investigation to understand the roles of stemness regulation. By recognizing that a group of stem cell marker genes shows developmentally decreased levels of expression ${ }^{11,18}$, the question of whether the expression levels of stem cell marker genes are related to the regenerative potential of injured neurons in adult animals can be answered. In addition, recent studies have shown that stem cell marker genes or their protein products are related to neurodegenerative disorders such as Alzheimer's disease. For example, strong immunoreactivity indicated by anti-Msi1 staining was found in neurofibrillary tangle-bearing neurons in the hippocampus of patients with Alzheimer's disease $(\mathrm{AD})^{92}$. Moreover, the Msi-1 protein was present in an oligomeric state in $\mathrm{AD}$ brains, forming aggregates ${ }^{93}$. In addition, Notch1 expression was significantly higher in the hippocampus of patients with amyotrophic lateral sclerosis (ALS), although the immunoreactivity of NICD was lower, suggesting that the Notch pathway is inactivated $^{94}$. However, the Notch pathway was abnormally overactivated in the spinal cords of sporadic ALS and ALS model mice ${ }^{95}$, suggesting that aberrant Notch pathway activation contributes to ALS pathogenesis. These reports clearly show that the Notch pathway and its related effectors are potential targets for understanding axon regeneration and degeneration ${ }^{96}$. CD44 expression in astrocytes and microglia is also known to be associated with ALS progression in a mouse model ${ }^{97}$, suggesting that the molecular interplay between stem cell marker genes from the nervous system needs to be investigated.

As indicated above, stem cell-associated genes are known to be differentially expressed in injured neurons or to display functions that regulate axon regeneration. Therefore, stem cell marker genes are potential candidates to manipulate for determining axon regenerative capacity in vitro and in vivo and to find downstream effector molecules that regulate regeneration, similar to the study on the Notch pathway in axon regeneration ${ }^{81}$. Although more research needs to be performed to gain a full understanding of the molecular connections between cellular stemness, the expression of stem cell marker genes, and neuronal regenerative potential, stemness and its related genes are potential targets to study molecular mechanisms regulating axon regeneration. Manipulating the expression levels of stem cell-associated genes that are selected from comparative transcriptomic data is one way to initiate this research. As a number of stem cell marker genes are transmembrane proteins, including Prom1, CD44, and Notch1, understanding the molecular mechanisms of membrane-associated stem cell markers that may lead to therapeutic applications may be realized 


\section{by identifying ligand-like molecules regulating axon regeneration via membrane proteins.}

\section{Acknowledgements}

The authors thank Zehra Alibasic for critical reading the manuscript. This work was supported by the National Research Foundation of Korea funded by the Korean Ministry of Science, Information and Communication Technology and Future Planning (Grant 2015R1A5A1009024 to Y.C.).

\section{Conflict of interest}

The authors declare that they have no conflict of interest.

\section{Publisher's note}

Springer Nature remains neutral with regard to jurisdictional claims in published maps and institutional affiliations.

Received: 8 October 2020 Accepted: 16 November 2020 Published online: 14 January 2021

\section{References}

1. Smith, D. S. \& Skene, J. H. A transcription-dependent switch controls competence of adult neurons for distinct modes of axon growth. J. Neurosci. 17 646-658 (1997).

2. Ma, T. C. \& Willis, D. E. What makes a RAG regeneration associated? Front. Mol. Neurosci. 8, 1-13 (2015).

3. Sun, F. \& He, Z. Neuronal intrinsic barriers for axon regeneration in the adult CNS. Curr. Opin. Neurobiol. 20, 510-518 (2010).

4. He, Z. \& Jin, Y. Intrinsic control of axon regeneration. Neuron 90,437-451 (2016).

5. Mahar, M. \& Cavalli, V. Intrinsic mechanisms of neuronal axon regeneration. Nat. Rev. Neurosci. 19, 323-337 (2018).

6. Mar, F. M., Bonni, A. \& Sousa, M. M. Cell intrinsic control of axon regeneration. EMBO Rep. 15, 254-263 (2014).

7. Yiu, G. \& He, Z. Glial inhibition of CNS axon regeneration. Nat. Rev. Neurosci. 7 617-627 (2006)

8. Shin, J. E. \& Cho, Y. Epigenetic regulation of axon regeneration after neura injury. Mol. Cells 40, 10-16 (2017).

9. Chandran, V. et al. A systems-level analysis of the peripheral nerve intrinsic axonal growth program. Neuron 89, 956-970 (2016).

10. Dulin, J. N. et al. Transcriptomic approaches to neural repair. J. Neurosci. $\mathbf{3 5}$ 13860-13867 (2015)

11. Tedeschi, A. et al. The calcium channel subunit Alpha2delta2 suppresses axon regeneration in the adult CNS. Neuron 92, 419-434 (2016).

12. Cai, J., Weiss, M. L. \& Rao, M. S. In search of 'stemness'. Exp. Hematol. 32 585-598 (2004)

13. Takahashi, K. \& Yamanaka, S. Induction of pluripotent stem cells from mouse embryonic and adult fibroblast cultures by defined factors. Cell 126, 663-676 (2006).

14. Lee, J. H. et al. Single transcription factor conversion of human blood fate to NPCs with CNS and PNS developmental capacity. Cell Rep. 11, 1367-1376 (2015).

15. Hou, S. \& Lu, P. Direct reprogramming of somatic cells into neural stem cells or neurons for neurological disorders. Neural Regen. Res. 11, 28-31 (2016).

16. Li, H. \& Chen, G. In Vivo reprogramming for CNS repair: regenerating neurons from endogenous glial cells. Neuron 91, 728-738 (2016).

17. Victor, M. B. et al. Generation of human striatal neurons by MicroRNA dependent direct conversion of fibroblasts. Neuron 84, 311-323 (2014).

18. Lee, J. et al. The stem cell marker Prom1 promotes axon regeneration by down-regulating cholesterol synthesis via Smad signaling. Proc. Natl Acad. Sci. U. S. A. 117, 15955-15966 (2020)

19. Jo, A. et al. The versatile functions of Sox9 in development, stem cells, and human diseases. Genes Dis. 1, 149-161 (2014).

20. Sun, W. et al. SOX9 is an astrocyte-specific nuclear marker in the adult brain outside the neurogenic regions. J. Neurosci. 37, 4493-4507 (2017).

21. Balakrishnan, A. et al. Temporal analysis of gene expression in the murine schwann cell lineage and the acutely injured postnatal nerve. PLOS ONE 11 $1-32$ (2016)
22. Sottile, V., Li, M. \& Scotting, P. J. Stem cell marker expression in the Bergmann glia population of the adult mouse brain. Brain Res. 1099, 8-17 (2006).

23. Mckillop, W. M., Dragan, M., Schedl, A. \& Brown, A. Conditional Sox9 ablation reduces chondroitin sulfate proteoglycan levels and improves motor function following spinal cord injury. Glia 61, 164-177 (2013).

24. Shin, J. E., Ha, H., Kim, Y. K., Cho, Y. \& DiAntonio, A. DLK regulates a distinctive transcriptional regeneration program after peripheral nerve injury. Neurobiol. Dis. 127, 178-192 (2019)

25. Shin, J. E., Ha, H., Cho, E. H., Kim, Y. K. \& Cho, Y. Comparative analysis of the transcriptome of injured nerve segments reveals spatiotemporal responses to neural damage in mice. J. Comp. Neurol. 526, 1195-1208 (2018).

26. Kaneko, Y. et al. Musashi1: an evolutionally conserved marker for CNS progenitor cells including neural stem cells. Dev. Neurosci. 22, 139-153 (2000).

27. Sakakibara, S. \& Okano, H. Expression of neural RNA-binding proteins in the postnatal CNS: implications of their roles in neuronal and glial cell development. J. Neurosci. 17, 8300-8312 (1997).

28. Sakakibara, S. I. et al. Mouse-Musashi-1, a neural RNA-Binding protein highly enriched in the mammalian CNS stem cell. Dev. Biol. 176, 230-242 (1996).

29. Sakakibara, Sichi et al. RNA-binding protein Musashi family: roles for CNS stem cells and a subpopulation of ependymal cells revealed by targeted disruption and antisense ablation. Proc. Natl Acad. Sci. U. S. A. 99. 15194-15199 (2002).

30. Kuwako, Kichiro et al. Neural RNA-binding protein Musashi1 controls midline crossing of precerebellar neurons through posttranscriptional regulation of Robo3/Rig-1 expression. Neuron 67, 407-421 (2010).

31. Chernoff, E. A. G., Sato, K., Salfity, H. V. N., Sarria, D. A. \& Belecky-Adams, T. Musashi and plasticity of xenopus and axolotl spinal cord ependymal cells. Front. Cell. Neurosci. 12, 1-23 (2018).

32. Chen, $\mathrm{L}$. et al. Axon regeneration pathways identified by systematic genetic screening in C. elegans. Neuron 71, 1043-1057 (2011).

33. Hentze, M. W., Castello, A., Schwarzl, T. \& Preiss, T. A brave new world of RNAbinding proteins. Nat. Rev. Mol. Cell Biol. 19, 327-341 (2018).

34. Yin, A. \& Miraglia, S. AC133, a novel marker for human hematopoietic stem and progenitor cells. Blood 90, 5002-5012 (1997).

35. Miraglia, S., Godfrey, W., Yin, A. \& Al, E. A novel five-transmembrane hematopoietic stem cell antigen: isolation, characterization, and molecular cloning. Blood 90, 5013-5021 (1997).

36. Corbeil, D. et al. The human AC133 hematopoietic stem cell antigen is also expressed in epithelial cells and targeted to plasma membrane protrusions. J. Biol. Chem. 275, 5512-5520 (2000).

37. Reichert, D. et al. Tunneling nanotubes mediate the transfer of stem cell marker CD133 between hematopoietic progenitor cells. Exp. Hematol. $\mathbf{4 4}$ 1092-1112.e2 (2016)

38. Permanyer, J. et al. Autosomal recessive retinitis pigmentosa with early macular affectation caused by premature truncation in PROM1. Investig. Ophthalmol. Vis. Sci. 51, 2656-2663 (2010).

39. Zacchigna, S. et al. Loss of the cholesterol-binding protein prominin-1/CD133 causes disk dysmorphogenesis and photoreceptor degeneration. J. Neurosci. 29, 2297-2308 (2009)

40. Walker, T. L. et al. Prominin-1 allows prospective isolation of neural stem cells from the adult murine hippocampus. J. Neurosci. 33, 3010-3024 (2013).

41. Nishide, K., Nakatani, Y., Kiyonari, H. \& Kondo, T. Glioblastoma formation from cell population depleted of prominin1-expressing cells. PLOS ONE 4, e6869 (2009).

42. Kamei, N. et al. Ex-vivo expanded human blood-derived CD133+ cells promote repair of injured spinal cord. J. Neurol. Sci. 328, 41-50 (2013).

43. Li, Z. CD133: a stem cell biomarker and beyond. Exp. Hematol. Oncol. 2 (2013).

44. Lan, X. et al. CD133 silencing inhibits stemness properties and enhances chemoradiosensitivity in CD133-positive liver cancer stem cells. Int. J. Mol. Med. 31, 315-324 (2013)

45. Li, S., Yang, L, Selzer, M. E. \& Hu, Y. Neuronal endoplasmic reticulum stress in axon injury and neurodegeneration. Ann. Neurol. 74, 768-777 (2013).

46. Dahlstrand, J., Zimmerman, L. B. McKay, R. D. G. \& Lendahl, U. Characterization of the human nestin gene reveals a close evolutionary relationship to neurofilaments. J. Cell Sci. 103, 589-597 (1992).

47. Hockfield, S. \& McKay, R. D. G. Identification of major cell classes in the developing mammalian nervous system. J. Neurosci. 5, 3310-3328 (1985).

48. Charalambous, P., Hurst, L. A. \& Thanos, S. Engrafted chicken neural tubederived stem cells support the innate propensity for axonal regeneration within the rat optic nerve. Investig. Ophthalmol. Vis. Sci. 49, 3513-3524 (2008). 
49. Mii, S. et al. Nestin-expressing stem cells promote nerve growth in long-term 3-dimensional Gelfoam ${ }^{\circledR}$-Supported Histoculture. PLOS ONE 8, e67153 (2013).

50. Bott, C. J. et al. Nestin in immature embryonic neurons affects axon growth cone morphology and Semaphorin3a sensitivity. Mol. Biol. Cell 30, 1214-1229 (2019).

51. Bernal, A. \& Arranz, L. Nestin-expressing progenitor cells: function, identity and therapeutic implications. Cell. Mol. Life Sci. 75, 2177-2195 (2018).

52. Manetto, V., Sternberger, N. H., Perry, G., Sternberger, L. A. \& Gambetti, P. Phosphorylation of neurofilaments is altered in amyotrophic lateral sclerosis. J. Neuropathol. Exp. Neurol. 47, 642-653 (1988).

53. Bancher, C. et al. An antigenic profile of Lewy bodies: immunocytochemical indication for protein phosphorylation and ubiquitination. J. Neuropathol. Exp. Neurol. 48, 81-93 (1989).

54. Figlewicz, D. A. et al. Variants of the heavy neurofilament subunit are associated with the development of amyotrophic lateral sclerosis. Hum. Mol. Genet 3, 1757-1761 (1994).

55. Jing, R., Pizzolato, G., Robson, R. M., Gabbiani, G. \& Skalli, O. Intermediate filament protein synemin is present in human reactive and malignant astrocytes and associates with ruffled membranes in astrocytoma cells. Glia 50, 107-120 (2005).

56. Noetzel, E. et al. Intermediate filament dynamics and breast cancer: aberrant promoter methylation of the Synemin gene is associated with early tumor relapse. Oncogene 29, 4814-4825 (2010).

57. Müller, M. et al. Dominant cataract formation in association with a vimentin assembly disrupting mutation. Hum. Mol. Genet. 18, 1052-1057 (2009).

58. Gros-Louis, F. et al. A frameshift deletion in peripherin gene associated with amyotrophic lateral sclerosis. J. Biol. Chem. 279, 45951-45956 (2004).

59. Lépinoux-Chambaud, C. \& Eyer, J. Review on intermediate filaments of the nervous system and their pathological alterations. Histochem. Cell Biol. 140, 13-22 (2013).

60. Liem, R. K. H. \& Messing, A. Dysfunctions of neuronal and glial intermediate filaments in disease. J. Clin. Invest. 119, 1814-1824 (2009).

61. Didonna, A. \& Opal, P. The role of neurofilament aggregation in neurodegeneration: lessons from rare inherited neurological disorders. Mol. Neurodegener. 14, 1-10 (2019).

62. Eide, T. et al. Protein kinase A-anchoring protein AKAP95 interacts with MCM2, a regulator of DNA replication. J. Biol. Chem. 278, 26750-26756 (2003).

63. Pruitt, S. C., Bailey, K. J. \& Freeland, A. Reduced Mcm2 Expression Results in Severe Stem/Progenitor Cell Deficiency and Cancer. Stem Cells 25, 3121-3132 (2007).

64. Carroll, T. D., Newton, I. P., Chen, Y., Blow, J. J. \& Näthke, I. Lgr5+ intestinal stem cells reside in an unlicensed G1 phase. J. Cell Biol. 217, 1667-1685 (2018).

65. Mohan, A., Kandalam, M., Ramkumar, H. L., Gopal, L. \& Krishnakumar, S. Stem cell markers: ABCG2 and MCM2 expression in retinoblastoma. Br. J. Ophthalmol. 90, 889-893 (2006).

66. Zhang, J. \& Jiao, J. Molecular biomarkers for embryonic and adult neural stem cell and neurogenesis. Biomed. Res. Int. 2015, 727542 (2015).

67. Hui, S. P. et al. Genome wide expression profiling during spinal cord regeneration identifies comprehensive cellular responses in zebrafish. PLOS ONE $\mathbf{9}$, e84212 (2014).

68. Zivraj, K. H. et al. Subcellular profiling reveals distinct and developmentally regulated repertoire of growth cone mRNAs. J. Neurosci. 30, 15464-15478 (2010).

69. Kumano, K. et al. Notch1 inhibits differentiation of hematopoietic cells by sustaining GATA-2 expression. Blood 98, 3283-3289 (2001).

70. Stier, S., Cheng, T., Dombkowski, D., Carlesso, N. \& Scadden, D. T. Notch1 activation increases hematopoietic stem cell self-renewal in vivo and favors lymphoid over myeloid lineage outcome. Blood 99, 2369-2378 (2002).

71. Umemoto, T. et al. Rat limbal epithelial side population cells exhibit a distinct expression of stem cell markers that are lacking in side population cells from the central cornea. FEBS Lett. 579, 6569-6574 (2005).

72. $Y u, X$. et al. Notch signaling activation in human embryonic stem cells is required for embryonic, but not trophoblastic, lineage commitment. Cell Stem Cell 2, 461-471 (2008).
73. Lütolf, S., Radtke, F., Aguet, M., Suter, U. \& Taylor, V. Notch 1 is required for neuronal and glial differentiation in the cerebellum. Development 129, 373-385 (2002).

74. Pierfelice, T., Alberi, L. \& Gaiano, N. Notch in the vertebrate nervous system: an old dog with new tricks. Neuron 69, 840-855 (2011).

75. Alberi, L. et al. Activity-induced notch signaling in neurons requires Arc/Arg3.1 and is essential for synaptic plasticity in hippocampal networks. Neuron 69, 437-444 (2011).

76. EIBejjani, R. \& Hammarlund, M. Notch signaling inhibits axon regeneration Neuron 73, 268-278 (2012).

77. Rao, S. N. R. \& Pearse, D. D. Regulating axonal responses to injury: the intersection between signaling pathways involved in axon myelination and the inhibition of axon regeneration. Front. Mol. Neurosci. 9, 1-28 (2016).

78. Yamamoto, N. et al. Role of Deltex-1 as a transcriptional regulator downstream of the notch receptor. J. Biol. Chem. 276, 45031-45040 (2001).

79. Chen, J., Leong, S. Y. \& Schachner, M. Differential expression of cell fate determinants in neurons and glial cells of adult mouse spinal cord after compression injury. Eur. J. Neurosci. 22, 1895-1906 (2005).

80. Yamamoto, S. I. et al. Transcription factor expression and notch-dependent regulation of neural progenitors in the adult rat spinal cord. J. Neurosci. 21, 9814-9823 (2001).

81. Sobrido-Cameán, D. et al. Inhibition of gamma-secretase promotes axon regeneration after a complete spinal cord injury. Front. Cell Dev. Biol. 8, 1-9 (2020).

82. Romaus-Sanjurjo, D., Valle-Maroto, S. M., Barreiro-Iglesias, A., Fernández-López, B. \& Rodicio, M. C. Anatomical recovery of the GABAergic system after a complete spinal cord injury in lampreys. Neuropharmacology 131, 389-402 (2018).

83. Iso, T., Kedes, L. \& Hamamori, Y. HES and HERP families: multiple effectors of the Notch signaling pathway. J. Cell. Physiol. 194, 237-255 (2003).

84. Morath, I., Hartmann, T. N. \& Orian-Rousseau, V. CD44: More than a mere stem cell marker. Int. J. Biochem. Cell Biol. 81, 166-173 (2016).

85. Roszkowska, M. et al. CD44: A novel synaptic cell adhesion molecule regulating structural and functional plasticity of dendritic spines. Mol. Biol. Cell 27, 4055-4066 (2016).

86. Dzwonek, J. \& Wilczyński, G. M. CD44: Molecular interactions, signaling and functions in the nervous system. Front. Cell. Neurosci. 9, 1-9 (2015).

87. Sretavan, D. W., Feng, L., Puré, E. \& Reichardt, L. F. Embryonic neurons of the developing optic chiasm express L1 and CD44, cell surface molecules with opposing effects on retinal axon growth. Neuron 12, 957-975 (1994).

88. Raivich, G. et al. The AP-1 transcription factor c-Jun is required for efficient axonal regeneration. Neuron 43, 57-67 (2004).

89. Barker, R., Fawcett, J. \& Hutchinson, P. Axon regeneration in the central nervous system. Annu. Rev. Cell Dev. Biol. 34, 495-521 (2018).

90. Liu, K., Tedeschi, A., Park, K. K. \& He, Z. Neuronal intrinsic mechanisms of axon regeneration. Annu. Rev. Neurosci. 34, 131-152 (2011).

91. Curcio, M. \& Bradke, F. Axon regeneration in the central nervous system: facing the challenges from the inside. Annu. Rev. Cell Dev. Biol. 34, 495-521 (2018).

92. Lovell, M. A. \& Markesbery, W. R. Ectopic expression of Musashi-1 in Alzheimer disease and Pick disease. J. Neuropathol. Exp. Neurol. 64, 675-680 (2005).

93. Sengupta, U. et al. Formation of toxic oligomeric assemblies of RNA-binding protein: Musashi in Alzheimer's disease. Acta Neuropathol. Commun. 6, 113 (2018).

94. Gómez-Pinedo, U. et al. Notch signalling in the hippocampus of patients with motor neuron disease. Front. Neurosci. 13, 302 (2019).

95. Nonneman, A. et al. Astrocyte-derived Jagged-1 mitigates deleterious Notch signaling in amyotrophic lateral sclerosis. Neurobiol. Dis. 119, 26-40 (2018).

96. Ho, D. M., Artavanis-Tsakonas, S. \& Louvi, A. The Notch pathway in CNS homeostasis and neurodegeneration. Wiley Interdiscip. Rev. Dev. Biol. 9, e358 (2020).

97. Matsumoto, T. et al. CD44 expression in astrocytes and microglia is associated with ALS progression in a mouse model. Neurosci. Lett. 520, 115-120 (2012). 